\title{
The separate effects of self-estimated and actual alcohol intoxication on risk-taking: A field experiment
}

\author{
Cortés Aguilar*, Alexandra; Espín, Antonio M.**; Exadaktylos, Filippos**; \\ Oyediran, Olusegun A.***; Palacio García, Luis Alejandro*; Proestakis, Antonios**
}

First Version ("Alcohol Consumption and Risk Attitude"): October 2008

This Version: May 2012

\begin{abstract}
Many risky actions are carried out under the influence of alcohol. However, the effect of alcoholic intoxication over the willingness to take risks is complex and still remains unclear. We conduct an economic field experiment in a natural, drinking and risk-taking environment to analyze how both actual and self-estimated blood alcohol concentration (BAC) levels influence subjects' choices over monetary lotteries. Our results reveal a negative impact of both actual and self-estimated BAC levels on risk-taking. However, for male and young subjects, we find a positive relationship between BAC underestimation (a pattern of estimation error which mainly occurs at high BAC levels) and the willingness to choose riskier lotteries. Our findings suggest that a risk compensation mechanism is activated only when individuals' own intoxication level is consciously self-perceived to be high. We conclude therefore that human propensity to engage in risky activities under the influence of alcohol is not due to an enhanced preference for risky choices. In addition to the suggestion in the existing literature that such propensity is due to a weakened ability to perceive risks, our results indicate that an impaired self-perception of own intoxication level may also be an important factor.
\end{abstract}

Keywords: risk taking, field experiment, alcohol intoxication, self-estimation

JEL Codes: C93, D81, D84, 110

\footnotetext{
- The authors are thankful to Pablo Brañas-Garza, Juan Antonio Lacomba, Nikolaos Georgantzís, and Francisco Lagos for their useful comments on earlier drafts, colleagues at the Department of Economics of the University of Granada for insightful discussions and participants in the discussion groups at the AEW 2008, SAE 2008, and IMEBE 2009. Any remaining errors are of course ours. Financial support from the Spanish Ministry of Science and Innovation (SEJ2010-17049/ECON), the Regional Programs SEJ-02547, SEJ-340 and SEJ-023 of the Regional Government of Andalusia are also gratefully acknowledged.

* Escuela de Economía y Administración, Universidad Industrial de Santander, Bucaramanga, Colombia.

** Departamento de Teoría e Historia Economica, Universidad de Granada, Granada, Spain.

*** Departamento de Análisis Económico y Finanzas, Universidad de Castilla La Mancha, Albacete, Spain.
} 


\section{Introduction}

The prominent role of alcohol in human life and its attendant socio-economic and health implications have attracted the research interests of many scholars. During the last five decades, many studies have been carried out in this realm. A great deal of attention has focused on the visible effect of alcoholic intoxication on risky and hazardous behaviors like criminal or aggressive activities (Ensor and Godfrey 1993; Lau et al. 1995; Richardson and Budd 2003), dangerous/risky driving patterns (Burian et al. 2003; Russ et al. 1988; Beirness 1987), risky sexual behavior (Halpern-Felsher et al. 1996; Cooper 2002) or excessive gambling (Sjoberg 1969; Cutter et al. 1973; Meier et al. 1996).

The great majority of these studies share three main characteristics. Firstly, the main focus is usually on the direct pharmacological effects of alcohol administration, leaving other important aspects related to short-term, post-consumptive behavior uninvestigated. One of such crucial parameters is the perception individuals hold about their own alcoholic intoxication levels; a psychological component that has not been studied in depth so far. A second characteristic, emanating from their focus, is the methodology used in these studies. Traditionally, research on the effects of alcohol ingestion is carried out through laboratory-based experiments (Meier et al 1996; Lane et al. 2004; Breslin et al. 1999). However, the behavioral effects of alcohol undoubtedly arise from other dimensions of its consumption other than simple pharmacological effects. For instance, the psychological and emotional state of drinkers, the social as well as the physical environment, or the laws and social norms governing a given occasion are all inseparable from alcohol-related behavioral patterns. Finally, when investigating the causal effects of alcohol on risky behavior, studies have used a wide range of risk-taking measures. Nevertheless, previous research has fallen short of distinguishing between how alcohol affects risk preferences on the one hand, and risk perceptions (Weber 1997) or abilities/skills (Byrnes 1998) on the other.

To address the above issues, we ran a field experiment in a natural drinking environment. We gauged participants' blood alcohol concentration (BAC) levels and elicited their estimations about own BAC as a measure for self-perceived intoxication 
level (Beirness 1987). We then analyzed separately how each measure affects subjects' risk-taking behavior in a lottery task designed specifically for this purpose, which was free of both cognitive complexity and subjective perceptions of risk.

Although there is ample epidemiological and clinical evidence linking risky behaviors to the effects of alcoholic intoxication (Cherpitel 1999; Testa and Collins 1997; Donovan and Marlatt 1982; Ferguson and Horwood 2000), the exact relationship between alcohol and risk-taking at the individual level remains unclear. Experimental results exploring such a relationship have been inconclusive. For the time being, we know that alcohol induces maladaptive risky decision-making due to an impaired evaluation of the consequences of the existing alternatives/choices (Kyngdon and Dickerson 1999; Euser et al. 2011; Fromme et al. 1997; George et al. 2005; Lane et al. 2004).

Lane et al. (2004) found that an incorrect response to previous monetary losses led intoxicated individuals (two groups, reaching about $0.4 \mathrm{~g} / \mathrm{L}$ and $0.8 \mathrm{~g} / \mathrm{L}$ of $\mathrm{BAC}$ ) to choose more risky options despite being linked to long-run losses. In their experiment, the expected value (that is, $p u_{x}+(1-p) u_{y}$ where $p$ is the probability that event $x$ will occur and $u_{x}$ and $u_{y}$ are the respective payoffs for events $x$ and $y$ ) of the risky option was always below that of the non-risky one, which led risk-taking to be maladaptive. Nevertheless, the only way for subjects to adapt their choices was by considering their experience from previous rounds since the experimenters did not explicitly provide the probabilities corresponding to the two possible outcomes within the risky option. The effect of alcohol on subjects' working memory (Euser et al. 2011) and other perceptual factors may thus be behind the higher risk taken by intoxicated subjects in such a task.

To the best of our knowledge, no alcohol-related study has tackled the question of whether intoxication promotes human preference for risky choices per se- that is, the taste for choices which, not being less adaptive than others, are simply riskier in terms of greater outcome variance. If this is the case, then alcohol intake would trigger risk-taking in two different ways: intoxicated individuals would (i) misevaluate the negative consequences involved in risky choices (Lane et al. 2004; Euser et al. 2011), and (ii) for options perceived as being equally adaptive, prefer 
riskier choices more often than sober individuals. Additionally, it can also be the case that alcohol does not alter individuals' risk preferences - as reported by Meier et al. (1996) and Breslin et al. (1999) for intoxicated subjects carrying out repeated gambling tasks with known probabilities and fluctuant adaptiveness of risk. Even more, it has been shown that intoxicated individuals, for instance, take a longer time to complete the "Stroop's color and word" cognitive test (Stroop 1935) and thus keep the number of errors low (Gustafson and Källmén 1990). Along the same line, individuals perform better on a tracking task when expecting alcohol than when expecting placebo after having received the same alcoholic dose (Finnigan 1995). These last observations indicate that a similar compensation process might lead humans to attenuate the harmful effects of alcohol in decision-making under risk when high intoxication is correctly self-estimated (as suggested by Burian et al. 2003). Such a process would develop an aversion to more volatile, riskier choices when options are perceived as identically adaptive.

We therefore hypothesize that, apart from the actual intoxication level, what may also be driving risky behavior is the drinker's self-perceived intoxication level and probably the comparative relationship between the two as well. In the DUI (Driving Under the Influence) paradigm for instance, high levels of ethanol in the driver's blood are likely to impair his perceptual and psychomotor skills (reflexes, attention, and reaction time) (Mitchell 1985; Moskovitz and Robinson 1988). At the same time, what the driver expects about the level of his intoxication and the impairment of both his skills and judgment might also crucially affect his behavior (McMillen and Wells-Parker 1987). It is therefore possible that the level of under/overestimation of own intoxication represents a crucial parameter influencing risky decision making. Even though self-perception of alcoholic intoxication has featured in the research agenda of clinical researchers, inquiries have been mainly conducted using the placebo effect treatment (Ross and Pihl 1989; Marlatt and Rohsenow 1980). The implementation of a laboratory driving task using expectancy deception procedures by Burian et al. (2003) is a representative example of this methodology. The present study, however, is the first to explore the link between self-estimated intoxication and risk preferences, and measure how individuals' 
under/overestimations of their actual alcoholic intoxication levels influence behavior.

Also novel is the field methodology we employed. Indeed, the sterile environment of the laboratory does not provide for the relevant conditions and relationships found in the real world and thus excludes their scientific study (Thombs et al. 2003). It is known that the field poses several restrictions on the level of control over the phenomenon at study. However, looking at the other side of the same coin, along with new methodologies, new directions and opportunities for research arise. During the last years, within the relatively newly-born field of experimental economics, field experiments are accelerating in frequency. These experiments are aiming at the higher external validity of results and capturing critical environmental effects absent in laboratories (Harrison and List 2004). Applied to the present study field, economic experimental methodology offered important advantages over classical laboratory experiments: (i) experimental subjects did not self-select in the study; (ii) demand effects were minimized, regarding the subjects' concern of being enrolled in an experiment on the effects of alcohol or substance intake; (iii) alcohol consumption was done prior to the study with absolutely no involvement of the researchers; (iv) alcohol consumption and risk-taking took place in an environment where such behaviors are more natural; and $(v)$ according to a basic principle of experimental economics (saliency of rewards, Smith 1976), the elicitation of behavioral measures was monetarily incentivized.

After controlling for other personal and environmental variables, our statistical analysis revealed a significant negative relationship between the subjects' measured BAC levels and their willingness to choose riskier options from lotteries with constant and positive expected value. We also found a very similar influence of selfestimated BAC levels over lottery choice. Hence, our findings suggest a tendency for individuals to take less risky choices along with the increase in both actual and selfperceived intoxication as part of a compensation process (Bäckman and Dixon 1992). However, when digging into the relationship between actual and self-estimated BAC levels, we found that individuals tend to overestimate own BAC at low intoxication levels, but underestimate it at higher levels. Paradoxically, the extent of such underestimation was positively related to risky choices for male and young subjects. 
It is thus suggested that individuals engage in compensatory behavior insofar as their levels of intoxication are conscientiously self-perceived to be high. The finding that underestimating own intoxication level can spur risky choices in male and young subpopulations indicates that the relationship between alcohol intake and risk-taking is not clear-cut, and that self-perceived intoxication could emerge as a crucial factor to explore in future investigations.

\section{Design and Procedures}

\subsection{Recruitment \& timing}

The experiment took place from May $22^{\text {nd }}$ to May $24^{\text {th }} 2008$ around the amusement kiosks ((Supporting) Figure S1) at the yearly festival of Granada (Spain) called the "Feria del Corpus Christi". Potential subjects were randomly approached by the same principal interviewer (a native of Granada) and asked to participate in a study for the local university which would give them the opportunity to earn up to $€ 60 .^{1}$ From a total of 73 participation requests, 71 individuals responded affirmatively and were finally recruited $^{2}$; a fact that removes any kind of selfselection bias concerns. First stage instructions were given by the principal interviewer to groups of at most three individuals. However, all participants made their decisions individually, which were then revealed to only one of the three experimenters, thus ensuring independence among individual decisions.

Upon acceptance, subjects chose the lottery of their preference (the one which they would later play), which constitutes the risk measurement of the study. A short questionnaire was then administered to gather information about subjects' height, weight, age, gender, drinking habits (average number of standard drink units per drinking occasion), use of marijuana (within the last three hours), and previous experience with alcohol measurement (number of times subjects had previously used an alcoholmeter). Up to this point, subjects had no clue that the research focus

\footnotetext{
${ }^{1}$ Although we were aware of the possibility of creating a focal point $(€ 60)$ by revealing subjects' potential earnings, we used such a recruitment strategy to make participation more likely.

${ }^{2}$ All participants gave their explicit verbal consent before proceeding. They were also informed that they were allowed to opt out of the experiment at any time. Additionally, upon payment, all subjects signed a receipt stating ex-post their written approval.
} 
of this study was alcohol intake; this prevented any experimental demand effects. Soon after completing the questionnaire and before implementing the lottery, subjects were asked whether they would like to participate in another (surprise) task which offered the possibility of earning an additional $€ 5$ if they correctly guessed their BAC levels. After accepting to participate, all 71 subjects received the additional information on this extra task and subsequently made estimations of their BAC levels. The experimental process ended with the subject's actual BAC measurement, implementation of the chosen lottery and finally the payment. The timeline describing the sequence of events of the experiment is depicted in Figure 1.

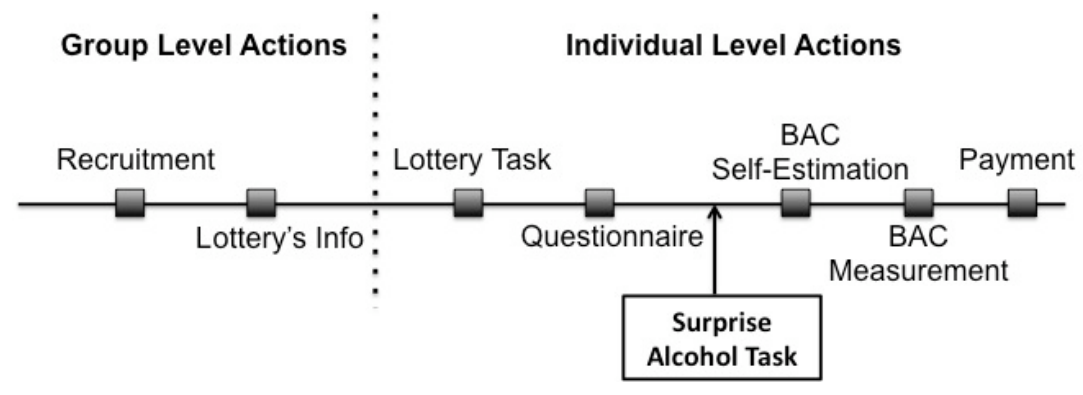

Figure 1. Timeline of the experiment

\subsection{The field}

Traditionally, local festivals in Spain are typical places for having fun, and involve, among others, folkloric activities, gambling games and alcohol consumption. Such an environment offers ideal and convivial conditions for the research purposes of our study. The "Feria del Corpus Christi" is the most popular festival in Granada, attracting all sorts of people and therefore minimizing any possible sample bias. Our final sample was comprised of individuals having consumed from zero up to large amounts of alcohol, who, moreover, had done so on their own and prior to any knowledge of participation in a study. The highest BAC levels present in our sample are hardly reached by dose-administration in laboratory settings for ethical and technical reasons. In addition, the lottery game used to measure risky behavior fitted perfectly to the general "playful" environment of the festival, diminishing in this way any experimentation flaws (e.g., demand effects). 
The field allows behaviors connected with alcohol consumption and risk-taking to develop naturally in a way that the laboratory would not. To further investigate the role of the environment on behavioral expressions, we ran two separate sessions corresponding to different affect cues and behavioral dispositions. The first one $(n=46)$, which we call the family session, took place on Thursday May $22^{\text {nd }}$ at around 8:00-11:00 p.m. when the festival was more family oriented. The second one $(n=25)$, denoted the party session, took place on Saturday May $24^{\text {th }}$ after midnight at around 1:00-4:00 a.m. in an evidently party-mood atmosphere.

Finally, one disadvantage related to the nature of this field experiment was the lack of information regarding the time and the general conditions surrounding the subject's alcohol consumption. However, BAC levels obtained from breath samples is probably the most reliable and realistic measure of alcoholic intoxication in the field, and is normally used by authorities and firms to detect intoxicated drivers or employees, respectively.

\subsection{Measuring risk attitudes}

Participants' risk preferences were measured by subjects' unique choice over six different lotteries, which corresponded to different potential payoffs (prizes) and winning probabilities but to the same expected value. Table 1 presents the main characteristics of the six lotteries. Starting with the zero-risk lottery $(100 \%$ of earning $€ 10)$ on the left of the table, winning probabilities gradually decrease in a simple fashion as we move to the right. In contrast to other alcohol-risk studies (Lane et al. 2004; Kyngdon and Dickerson 1999; Euser et al. 2011; Fromme et al. 1997; George et al. 2005), in this task risk taking is not maladaptive; the expected value across all lotteries is purposely kept constant at $€ 10$ by increasing the potential prize in each lottery in proportion to the risk increase.

Our lottery-task is a simpler and more visual version of the risk-taking measure by Sabater-Grande and Georgantzís [36] (setting $r=0)^{3}$. Risk-taking increases along with the probability assigned to the less favorable payoff, which is always zero. Thus, choosing the lot-60 corresponds to higher risk-taking behavior (in ordinal rather than

\footnotetext{
${ }^{3}$ This measure is in accordance with several risk-taking theories. Nevertheless, under expected utility assumptions, our measure fails to identify the lottery choice of a risk-neutral agent.
} 
in quantifiable terms) compared to choosing any other lottery. Accordingly, lot-50 is chosen by a person who exhibits lower risk-taking behavior than subjects choosing lot-60, but higher compared to persons who choose lot-40 or less. Obviously, choosing lot-10 is considered the least risk-taking behavior.

In designing the lottery-choice task, we responded to a tradeoff between richness of information of subjects' risk preferences and simplicity. Especially in a field context complexity implies noise on the data (see the relevant discussions on Andersen et al. 2010 and Dave et al. 2010). Moreover, in this particular experiment simplicity was a key feature of the design since controlling for risk perceptions was principal to the study. Our measure provides sufficient heterogeneity.

Lotteries were represented by six different boxes (Figure S2) with visible colored balls inside. Every box contained one winning, yellow ball and a different number of non-winning, pink balls. Lot-10 contained no pink balls, lot-20 contained only one, and lot-30 contained two pink balls and so on until lot-60, with five nonwinning, pink balls. Each participant had to select one box. The content of the selected box was dropped into an opaque bag, from which the participant was allowed to pick only one ball that determined the lottery's final outcome.

\begin{tabular}{c|cccccc} 
Lottery & 10 & 20 & 30 & 40 & 50 & 60 \\
\hline Probability & $100 \%$ & $50 \%$ & $33 \%$ & $25 \%$ & $20 \%$ & $17 \%$ \\
Prize & 10 & 20 & 30 & 40 & 50 & 60 \\
Exp. Payoff & 10 & 10 & 10 & 10 & 10 & 10
\end{tabular}

Table 1. Features of the risk-taking task

This game-like task was selected due to its visual simplicity and its appropriateness to the festive environment hosting our study. Special care was taken to ensure the ease of comprehensibility of the task by presenting the winning probabilities and natural frequencies in an easily visible way. In this way, we managed to factor out any subjective effect related to individuals' risk perception. Moreover, contrary to other risk-taking measures such as driving tasks (e.g., Mitchell 1985; Moskovitz and Robinson 1988) or more complex lotteries (e.g., Meier et al. 
1996; Breslin et al. 1999), subjects' cognitive abilities or skills should not influence decision making.

According to standard practices in experimental economics, the task was monetarily incentivized procuring dominance, monotonicity and saliency (Induced Value Theory, Smith 1976). Incentive compatibility ensures that subjects truthfully reveal their private values. Real incentives are particularly relevant in the case of risk-related analyses (Slovic 1969).

\subsection{Measuring actual and self-estimated blood alcohol concentration}

The surprise BAC self-estimation (eBAC henceforth) task took place upon agreement by the subjects after completion of the questionnaire and before taking the BAC measurement. BAC was measured in $\mathrm{g} / \mathrm{L}$ using an ACE-AL 6000 breathalyzer after subjects rinsed their mouth with mineral water for 30 seconds. In order to induce common information and reference points about alcoholic intoxication measurement across subjects, we informed participants (i) that the maximum permitted BAC when driving is $0.5 \mathrm{~g} / \mathrm{L}$ under the Spanish traffic law; (ii) about the official correspondence between a unit of alcoholic drink (beer) and its effect on the BAC of an average weighted male or female; and (iii) that BAC depends on individuals' weight, the time-gap between alcohol consumption and BAC measurement and the food ingested.

Monetary incentives were also introduced in this task. Subjects would win an additional $€ 5$ note if they were able to approximate their actual BAC within an allowed deviation of $\pm 0.1 \mathrm{~g} / \mathrm{L}$. Given the existing incentive for accuracy and the information tips provided, and after controlling for subjects' experience with an alcoholmeter, subjects' significant deviations from the actual BAC should be mainly driven by their self-perceived intoxication level due to alcohol intake. Beirness (1987) has reported that individuals who self-estimate lower levels of BAC

\footnotetext{
${ }^{4}$ Depending on the subject's gender, one of the following hints were given (according to the Spanish Directorate General for Traffic): a) For average weight women (60 kg), two small glasses (250ml) of beer correspond to $0.5 \mathrm{~g}$. of alcohol per blood lt. b) For average weight men (70 kg), two tube-glasses $(333 \mathrm{ml})$ of beer correspond to $0.5 \mathrm{~g}$. of alcohol per blood lt.
} 
systematically "feel" themselves to be less intoxicated, which suggests a direct relationship between both measures. Moreover, self-estimated BAC, as opposed to self-reported intoxication, is quantitatively comparable across subjects.

\subsection{Statistical analysis}

We first implemented non-parametric tests to highlight any interesting differences among individuals and sessions. Moreover, in order to study the impact of alcohol over risk taking, we controlled for such differences through an ordered logistic regression. The fact that our dependent variable - subjects' lottery choice $(10,20,30,40,50,60)$ - is both discrete and ordinal justifies the adequacy of such a model. Finally, linear and locally weighted regressions were performed to identify and explain other relationships when necessary.

\section{Results}

The sample under examination consists of 70 subjects $^{5}$ (40 males) aged between 18 and 59. Table 2 shows descriptive statistics for the participants in each experimental session and identifies significant differences between sessions obtained through a Mann-Whitney test. Participants in the family session were significantly younger $(P<0.05)$ and the reported BACs $(P<0.01)$, eBACs $(P<0.05)$, and drinks consumed per drinking occasion $(P<0.05)$ were significantly lower. As expected, different experimental sessions were associated with different drinking patterns, with the party environment being linked to more severe alcoholic consumption. Spearman's rank-order correlation reveals that subjects' self-reported alcohol habits - average number of standard drinks consumed per drinking occasion - positively correlates with $\mathrm{BAC}(\rho=0.44, P<0.01)$ and eBAC $(\rho=0.37, P<0.01)$.

\footnotetext{
${ }^{5}$ One subject was excluded from the sample for not satisfying independent decision-making (external influence from peers).
} 


\begin{tabular}{lcccccccc}
\hline SESSION & Obs & $\begin{array}{c}\text { Male } \\
(\mathbf{\%})\end{array}$ & $\begin{array}{c}\text { Age } \\
\mathbf{( y r})\end{array}$ & $\begin{array}{c}\text { BMI } \\
\left(\mathbf{k g} / \mathbf{m}^{2}\right)\end{array}$ & $\begin{array}{c}\text { BAC } \\
(\mathbf{g} / \mathbf{l})\end{array}$ & $\begin{array}{c}\boldsymbol{e} \mathbf{B A C} \\
(\mathrm{g} / \mathbf{l})\end{array}$ & $\begin{array}{c}\text { Alcohol } \\
\text { habits } \\
(\mathbf{d r i n k s})\end{array}$ & $\begin{array}{c}\text { Earning } \\
(\boldsymbol{\epsilon})\end{array}$ \\
\hline \hline Family & 45 & $\begin{array}{c}51.11 \\
( \pm 7.5)\end{array}$ & $\begin{array}{c}26.73 \\
( \pm 1.01)\end{array}$ & $\begin{array}{c}23.89 \\
( \pm 0.6)\end{array}$ & $\begin{array}{c}0.349 \\
( \pm 0.068)\end{array}$ & $\begin{array}{c}0.462 \\
( \pm 0.079)\end{array}$ & $\begin{array}{c}4.02 \\
( \pm 0.48)\end{array}$ & $\begin{array}{c}12.2 \\
( \pm 2.06)\end{array}$ \\
Party & 25 & $\begin{array}{c}68 \\
( \pm 9.52)\end{array}$ & $\begin{array}{c}30.88^{* *} \\
( \pm 1.67)\end{array}$ & $\begin{array}{c}24.04 \\
( \pm 0.81)\end{array}$ & $\begin{array}{c}0.76^{* * *} \\
( \pm 0.102)\end{array}$ & $\begin{array}{c}0.758^{* *} \\
( \pm 0.102)\end{array}$ & $\begin{array}{c}5.36 * * \\
( \pm 0.57)\end{array}$ & $\begin{array}{c}15.8 \\
( \pm 3.88)\end{array}$ \\
\hline \hline TOTAL & 70 & $\begin{array}{c}57.14 \\
( \pm 0.60)\end{array}$ & $\begin{array}{c}28.21 \\
( \pm 0.91)\end{array}$ & $\begin{array}{c}24.04 \\
( \pm 0.48)\end{array}$ & $\begin{array}{c}0.496 \\
( \pm 0.061)\end{array}$ & $\begin{array}{c}0.568 \\
( \pm 0.064)\end{array}$ & $\begin{array}{c}4.5 \\
( \pm 0.38)\end{array}$ & $\begin{array}{c}13.5 \\
( \pm 1.90)\end{array}$ \\
\hline
\end{tabular}

Table 2. Summary statistics by session. Mean values ( \pm SEM) of principal variables in each experimental session. Age, BMI, eBAC and alcohol habits are self-reported variables. The variable alcohol habits indicates the number of drinks consumed per drinking occasion. ${ }^{* *}$, *** indicate significantly higher rank of the variable in that session at the 0.05 and 0.01 level, respectively (Mann-Whitney test).

Measured BAC was zero for 26 (37.1\%) subjects, although only 15 (21.4\%) of them declared no alcoholic intake prior to the start of the experiment. Maximum values for $\mathrm{BAC}$ and $e \mathrm{BAC}$ were $1.8 \mathrm{~g} / \mathrm{l}$ and $2.5 \mathrm{~g} / \mathrm{l}$, respectively. We found a strong positive correlation between $\mathrm{BAC}$ and $e \mathrm{BAC}$ for both the whole sample $(\rho=0.73$, $P<0.01)$ and the subsample of subjects who declared having drunk alcohol before the experiment $(\rho=0.54, P<0.01, n=55)$. However, in line with previous studies on selfperceived intoxication (Thombs et al. 2003; Beirness et al. 1993), there exists an increasing propensity to underestimate own BAC level along with the increase of the actual level. Figure 2 shows a locally weighted regression (red line) of eBAC on BAC. The dashed line displays equal values of both variables. The crossing point of the two lines is around $0.82 \mathrm{~g} / \mathrm{l}$. Hence, for BACs lower than $0.82 \mathrm{~g} / \mathrm{l}$ subjects tended to overestimate their intoxication level, whereas they underestimated it for BACs above that value ${ }^{6}$. Similar results were obtained for the subsample of subjects $(n=55)$ who declared having ingested alcohol prior to the experiment (blue line).

\footnotetext{
${ }^{6}$ However, quadratic OLS regression supports the existence of a concave relationship between the two variables $(P<0.05)$ for the whole sample but not for the aforementioned subsample $(P>0.4)$ (available upon request). Using only their subsample of intoxicated subjects, Thombs et al. (2003) also failed to find a concave relationship.
} 


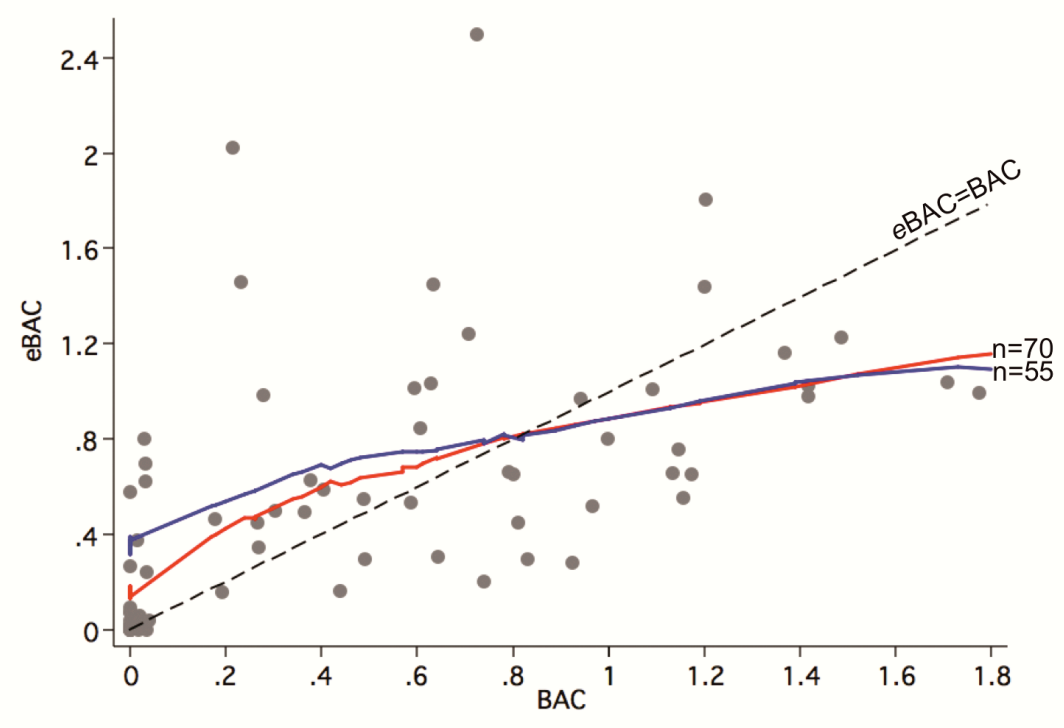

Figure 2. Lowess smoother of $e \mathrm{BAC}$ as function of BAC. Red and blue lines represent locally weighted regression of $e \mathrm{BAC}$ on BAC for the whole sample and for the subsample with $e \mathrm{BAC}>0$, respectively. For purposes of clarity, scatter dots are illustrated allowing for a $5 \%$ error.

In terms of risk profiles, $70 \%$ of subjects chose lotteries with a probability of success higher than $1 / 4$ - i.e. lotteries 10,20 , and 30 . The distribution of lottery choices is illustrated in Figure 3. Table 3 shows the impact of alcohol-related variables over risk-taking. We present coefficients estimated by ordered logistic regressions with subjects' lottery choice as the dependent variable. All the models are controlled for personal and environmental characteristics, which is crucial given the field source of the data. Column 1 reports the impact of BAC over the willingness to choose riskier lotteries, which is negative and significant $(P<0.05)$. eBAC was found to have a similar influence over the dependent variable $(P<0.05)$ (column 2$)$. The models in columns 4 and 5 depict significant interactions of $\mathrm{BAC}$ and $e \mathrm{BAC}$ with the other explanatory variables, respectively ${ }^{7}$. As model 4 shows, only the interaction of BAC with gender significantly influences the dependent variable $(P<0.05)$. A Wald test supported that the negative impact of BAC over lottery choice is significant for females $(P<0.01)$ but not for males $(P>0.8)$. The interaction of $e \mathrm{BAC}$ with gender,

\footnotetext{
${ }^{7}$ The remaining possible interactions were not significant at conventional levels $\left(P_{s}>0.1\right)$. Models with interaction terms are replicated with OLS methodology due to the complexity of nonlinear marginal effects in logistic regressions with interactions (Ai and Norton 2003). OLS regressions yield similar main results (upon request).
} 
however, did not yield significance, whereas its interaction with age did $(P<0.01)$ (column 5). The negative influence of $e \mathrm{BAC}$ over choosing riskier lotteries was found to be mainly due to younger subjects ( $P_{s}<0.05$ for all ages $<31$, Wald test).

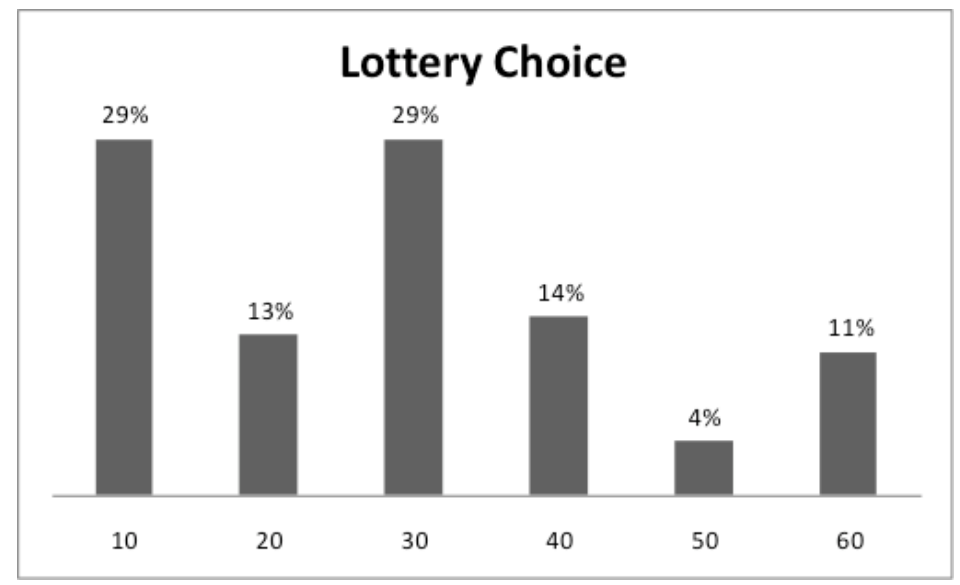

Figure 3. Distribution of lottery choices. Percentage of subjects choosing each of the six possible lotteries.

To analyze the influence triggered by under/overestimation of own BAC level on the dependent variable (columns 3 and 6), we reduced the sample to those subjects who declared having drunk alcohol before participating in our experiment $(n=55)$. Note that this subsample also includes subjects $(n=11)$ who declared a positive $\mathrm{BAC}$, but whose actual BAC proved to be zero after the measurements. Moreover, we constructed an index variable called underBAC, which simply captures the difference between $\mathrm{BAC}$ and $\mathrm{BAAC}$, such that the higher the value of underBAC, the larger the subject's underestimation level. This variable falls within the interval [$1.8,0.8$ ] with $43.64 \%$ of subjects actually underestimating their own BAC (that is, with underBAC>0). Although we found no significant effect of underBAC over the willingness to choose riskier lotteries (column 3), the interactions of underBAC with both gender $(P<0.05)$ and age $(P<0.01)$ yielded significant estimates (column 6$)$. A positive and significant effect of underestimation over the willingness to take risks for young male subjects under 30 years old $(n=23)$ was confirmed using the appropriate Wald tests (all $P_{s}<0.05$ ). On the contrary, the effect of underestimation over risk taking was negative and significant for female subjects over 33 years old (all Ps<0.05), although very few observations $(n=5)$ satisfied this condition. 


\begin{tabular}{|c|c|c|c|c|c|c|}
\hline \multicolumn{7}{|c|}{ Ordered Logistic Regressions } \\
\hline \multirow{2}{*}{$\begin{array}{l}\text { Dep. Variable: } \\
\text { Lottery choice }\end{array}$} & \multicolumn{3}{|c|}{ Main effects models } & \multicolumn{3}{|c|}{ Interaction effects models } \\
\hline & (1) & (2) & (3) & (4) & (5) & (6) \\
\hline BAC & $\begin{array}{c}-1.301 * * \\
(0.586)\end{array}$ & & & $\begin{array}{c}-2.388 * * * \\
(0.784)\end{array}$ & & \\
\hline$e \mathrm{BAC}$ & & $\begin{array}{l}-1.212 * * \\
(0.578)\end{array}$ & & & $\begin{array}{l}-6.6^{* * *} \\
(2.126)\end{array}$ & \\
\hline under $\mathrm{BAC}$ & & & $\begin{array}{c}0.383 \\
(0.534)\end{array}$ & & & $\begin{array}{c}7.709 * * \\
(3.26)\end{array}$ \\
\hline BAC $x$ male & & & & $\begin{array}{l}2.579 * * \\
(1.127)\end{array}$ & & \\
\hline$e \mathrm{BAC} \times$ age & & & & & $\begin{array}{c}0.172^{* * * *} \\
(0.065)\end{array}$ & \\
\hline under $B A C \mathrm{x}$ male & & & & & & $\begin{array}{l}3.055^{* *} \\
(1.516)\end{array}$ \\
\hline under $B A C \mathrm{x}$ age & & & & & & $\begin{array}{l}-0.3^{* * *} \\
(0.109)\end{array}$ \\
\hline male & $\begin{array}{l}-0.089 \\
(0.691)\end{array}$ & $\begin{array}{c}0.052 \\
(0.692)\end{array}$ & $\begin{array}{c}0.242 \\
(0.717)\end{array}$ & $\begin{array}{l}-0.585 \\
(0.966)\end{array}$ & $\begin{array}{l}0.372 \\
(0.72)\end{array}$ & $\begin{array}{l}1.367 \\
(0.995)\end{array}$ \\
\hline age & $\begin{array}{c}0.626^{* * *} \\
(0.213)\end{array}$ & $\begin{array}{c}0.598 * * * \\
(0.206)\end{array}$ & $\begin{array}{l}0.112 * * \\
(0.052)\end{array}$ & $\begin{array}{c}0.698^{* * *} \\
(0.233)\end{array}$ & $\begin{array}{l}0.533^{* *} \\
(0.227)\end{array}$ & $\begin{array}{l}0.812 * * \\
(0.409)\end{array}$ \\
\hline $\operatorname{age}^{2}$ & $\begin{array}{c}-0.008^{* * *} \\
(0.003)\end{array}$ & $\begin{array}{c}-0.008^{* * *} \\
(0.003)\end{array}$ & & $\begin{array}{c}-0.01 * * * \\
(0.003)\end{array}$ & $\begin{array}{c}-0.008^{* * *} \\
(0.003)\end{array}$ & $\begin{array}{l}-0.012 * \\
(0.006)\end{array}$ \\
\hline BMI & $\begin{array}{c}0.112 \\
(0.091)\end{array}$ & $\begin{array}{c}0.132 \\
(0.091)\end{array}$ & $\begin{array}{c}0.18^{*} \\
(0.101)\end{array}$ & $\begin{array}{c}0.135 \\
(0.096)\end{array}$ & $\begin{array}{c}0.074 \\
(0.095)\end{array}$ & $\begin{array}{l}0.219^{*} \\
(0.115)\end{array}$ \\
\hline alc. habits (drinks) & $\begin{array}{l}-0.023 \\
(0.076)\end{array}$ & $\begin{array}{l}-0.023 \\
(0.08)\end{array}$ & $\begin{array}{l}-0.131 \\
(0.087)\end{array}$ & $\begin{array}{l}-0.106 \\
(0.085)\end{array}$ & $\begin{array}{c}0.024 \\
(0.085)\end{array}$ & $\begin{array}{l}-0.217 * * \\
(0.103)\end{array}$ \\
\hline marijuana & $\begin{array}{l}-0.044 \\
(0.71)\end{array}$ & $\begin{array}{l}-0.067 \\
(0.733)\end{array}$ & $\begin{array}{c}0.159 \\
(0.799)\end{array}$ & $\begin{array}{c}0.18 \\
(0.73)\end{array}$ & $\begin{array}{l}-0.381 \\
(0.762)\end{array}$ & $\begin{array}{c}0.035 \\
(0.921)\end{array}$ \\
\hline party session & $\begin{array}{c}0.851 \\
(0.536)\end{array}$ & $\begin{array}{c}0.594 \\
(0.523)\end{array}$ & $\begin{array}{c}0.531 \\
(0.584)\end{array}$ & $\begin{array}{l}2.265^{* *} \\
(0.923)\end{array}$ & $\begin{array}{c}0.562 \\
(0.535)\end{array}$ & $\begin{array}{l}1.972 * \\
(1.093)\end{array}$ \\
\hline Party ses. $\mathrm{x}$ male & & & & $\begin{array}{c}-2.283 * * \\
(1.15)\end{array}$ & & $\begin{array}{l}-2.251^{*} \\
(1.311)\end{array}$ \\
\hline observations & 70 & 70 & 55 & 70 & 70 & 55 \\
\hline $\operatorname{LR}\left(\mathrm{chi}^{2}\right)$ & $21.28^{* * *}$ & $21.25^{* *}$ & $22.75^{* * *}$ & $28.14 * * *$ & $29.77^{* * *}$ & $38.05^{* * *}$ \\
\hline pseudo $\mathrm{R}^{2}$ & 0.0926 & 0.0925 & 0.1261 & 0.1225 & 0.1296 & 0.211 \\
\hline
\end{tabular}

Table 3: The impact of BAC and self-estimated BAC over the willingness to take risk. Standard errors in brackets. ${ }^{*}, * *, * * *$ indicate significance at the $0.10,0.05$, and 0.01 levels, respectively. Models 3 and 6 depicting the effect of underBAC are reduced to the subsample of subjects who declared having ingested alcohol before the experiment. Regressions including $e B A C$ and underBAC are additionally controlled for subject's experience with the alcoholmeter. Due to the reduced sample size, age squared and interactions between variables are excluded from those models in which their estimates are not significant in order to maximize the degrees of freedom of the models. In Table S1, regressions 2, 3, 5, 6 are repeated, excluding eBAC's outliers. No important differences were observed on the basic regressors. 
When performing an OLS regression on the continuous dependent variable underBAC (see Table S2) we found that for each level of BAC, younger individuals underestimate their own BAC level to a marginally significant higher extent $(P=0.075)$ than older ones. Following the same methodology and splitting the sample by gender, we realized that the impact of youth on underestimation was significant only for male subjects $(P<0.05, n=34)$. Therefore, young male subjects were more likely to underestimate their own intoxication levels and to consequently increase risk taking than female ones. Moreover, we found that non-heavy drinking males as measured by the number of drinks per drinking occasion - tended to underestimate their own BAC level $(P=0.055)$. On the other hand, no significant predictors of underestimation were found for females.

With regards to the control variables used in the previous logistic models, we can make the following comments. Firstly, unlike previous studies (e.g., Anderson and Mellor 2008), we found that the influence of age on risk-taking is significantly positive (although concave in most cases); a finding which can be attributed to the specific characteristics of our field experiment.

Secondly, the interaction between gender and experimental session (party or family) was found to be significant in two out of three models: while females were less willing to take risks in the family session than in the party session, no differences in willingness to take risks across sessions were detected for males. This result may be in line with the literature asserting that females' attitude toward risk is more context-dependent than that of males (Croson and Gneezy 2009). In this vein, the affect state triggered by the party environment of the nocturnal session and the one activated during the evening session seem to generate two different contexts for risk taking (Arkes et al. 1988; Isen and Patrick 1983; Kahn and Isen 1993; Moore and Chater 2003).

Finally, we found that subjects' BMI and alcohol habits (drinks per occasion) had a weak impact on the lottery choices for some models. The former was related positively and the latter negatively to the dependent variable. No main or interaction effect of marijuana use was found. It must be said, nevertheless, that this experiment was not designed to explore relationships other than those associated 
with alcoholic intoxication and risk preferences. Thus, whatever insights extracted from the last findings should be taken with caution.

\section{Discussion}

While most studies agree that alcohol consumption is associated with risky behavioral patterns like dangerous driving (Burian et al. 2003; Russ et al. 1988; Beirness 1987), risky sexual behavior (Halpern-Felsher et al. 1996; Cooper 2002) and violence (Ensor and Godfrey 1993; Lau et al. 1995; Richardson and Budd 2003), there is no consensus on exactly how alcohol influences an individual's willingness to take risks. On the one hand, it is still unclear whether the resulting risky behaviors after alcoholic exposure are due to an enhanced preference for riskier choices in concomitance with the impaired ability to perceive risks and/or to evaluate the possible negative consequences associated with those behaviors (Lane et al. 2004; Kyngdon and Dickerson 1999; Euser et al. 2011; Fromme et al. 1997; George et al. 2005). On the other hand, we still do not know whether it is only the pharmacological effect of alcohol intake or also a psychological component which influences alcohol-related risky behaviors. So far the role of important psychological factors around the alcohol-risk relationship remains surprisingly unexplored. Concretely, how high an individual perceives his own intoxication has not been deeply investigated as a factor intimately linked to risk-taking.

In this study, we report the results of an economic field experiment designed to study the effect of alcoholic intoxication over risk-taking in three different dimensions: we separately analyze how subjects' actual BAC, self-estimated BAC, and over/underestimation of own BAC influence their willingness to choose risky lotteries with real monetary incentives. The use of self-estimated BAC allows us to monetarily incentivize the elicitation of an individual's self-perceived intoxication by rewarding subjects' correct guesses about their own BAC levels. In addition, selfestimated BAC offers better comparability across subjects than self-reported intoxication. In any case, previous evidence suggests a direct relationship between both measures (Beirness 1987). 
Contrary to previous research based on risk-related behavioral games or gambling tasks - in which subjects' abilities play a role and often there is ambiguity about the exact risk involved across different choices - our design isolates subjects' willingness to take riskier choices as it minimizes the scope of different perceptions about the risk or negative consequences involved by choices across subjects. By implementing a simple lottery task we manage to reduce the effect of impaired cognitive abilities due to alcohol intoxication on subjects' decision making. In addition to that, we increase outcome variance along different lotteries and keep the expected value constant, positive, and easily computable across them. In this way, the differences between choices are uniquely based on the risk involved and not on different levels of long-term profitability (i.e., how comparatively adaptive the options are), learning or other required abilities. Lastly, given the field nature of our study, important environmental and individual features that may mediate or interact with the effects of alcohol over risk-taking are accounted for.

We find that both measured and self-estimated BAC levels impact negatively over the subjects' willingness to choose riskier lotteries. However, at high intoxication levels subjects tend to underestimate their own BAC, and the degree of such underestimation goes along with increasing the riskiness of choices for male and young subjects. Thus, our findings suggest that individuals take lower risks insofar as they consciously perceive their intoxication level to be high. This might work as a proximate mechanism for compensating the psychomotor impairment triggered by intoxication (Burian et al. 2003). Compensatory patterns after alcohol exposure have been reported in other behavioral tasks (Gustafson and Källmén 1990; Finnigan et al. 1995). Therefore, engagement in risky behaviors associated with alcoholic intoxication seems to be due to the impaired ability to evaluate risks and/or the negative consequences of choices when such impairment is not sufficiently compensated for as a result of an inadequately self-perceived intoxication level. Of major interest is the case of young and male individuals. Youth and maleness are considered two attributes that increase the likelihood of being involved in road accidents, and engaging in violent behavior and other risky patterns under the influence of heavy alcohol consumption (e.g., Goodman et al. 1986; Zador et al. 2000; Peck et al. 2008). Our findings suggest that the underestimation of own 
alcoholic intoxication level at high BAC levels could be behind the enhanced willingness to take risks in these particular population subgroups.

\section{Acknowledgements}

The authors are thankful to Pablo Brañas-Garza, Juan Antonio Lacomba, Nikolaos Georgantzís, and Francisco Lagos for their useful comments on earlier drafts, colleagues at the Department of Economics of the University of Granada for insightful discussions and participants in the discussion groups at the AEW 2008, SAE 2008, and IMEBE 2009. Any remaining errors are of course ours. Financial support from the Spanish Ministry of Science and Innovation (SEJ2010-17049/ECON), the Regional Programs SEJ-02547, SEJ-340 and SEJ-023 of the Regional Government of Andalusia are also gratefully acknowledged. 


\section{References}

Ai, C., \& Norton, E. (2003). Interaction terms in logit and probit models. Economics Letters, 80(1), 123129.

Andersen, S., Harrison, G.W., Lau, M.I., \& Rutström, E.E. (2010). Preference heterogeneity in experiments: Comparing the field and laboratory. Journal of Economic Behavior \& Organization, 73(2), 209-224.

Anderson, L.R., \& Mellor, J.M. (2008). Predicting health behaviors with an experimental measure of risk preference. Journal of Health Economics, 27(5), 1260-1274.

Arkes, H.A., Herren, L.T., \& Isen, A.M. (1988). The role of potential loss in the influence of affect on risk-taking behavior. Organizational Behavior and Human Decision Processes, 42(2), 181-193.

Bäckman, L. \& Dixon, R.A. (1992). Psychological compensation: A theoretical framework. Psychological Bulletin, 112(2), 259-283.

Beirness, D.J. (1987). Self-estimates of blood alcohol concentration in drinking-driving context. Drug and Alcohol Dependence, 19(1), 79-90.

Beirness, D.J., Foss, R.D., \& Voas, R.B. (1993). Drinking drivers' estimates of their own Blood Alcohol Concentration. Journal of Traffic Medicine, 21(2), 73-78.

Breslin, F.C., Sobell, M.B., Cappell, H., Vakili, S., \& Poulos, C.X. (1999). The effects of alcohol, gender, and sensation seeking on the gambling choices of social drinkers. Psychology of Addictive Behaviors, 13(3), 243-252.

Burian, S.E., Hensberry, R., \& Liguori, A. (2003). Differential effects of alcohol and alcohol expectancy on risk-taking during simulated driving. Human Psychopharmacology: Clinical and Experimental, 18(3), 175-184.

Byrnes, J.P. (1998). The nature and development of decision making. Erlbaum, Hillsdale, N.J.

Cherpitel CJ (1999) Substance use, injury and risk-taking dispositions in the general population. Alcoholism: Clinical and Experimental Research, 23(1), 121-126.

Cooper, M.L. (2002). Alcohol use and risky sexual behavior among college students and youth: evaluating the evidence. Journal of Studies on Alcohol, 14(Suppl.), 101-117.

Croson, R., \& Gneezy, U. (2009). Gender Differences in Preferences. Journal of Economic Literature, $47(2), 448-474$

Cutter, H.S.G., Green, L.R., \& Harford, T.C. (1973). Levels of risk taken by extraverted and introverted alcoholics as a function of drinking whisky. British Journal of Social and Clinical Psychology, 12(1), 8389.

Dave, C., Eckel, C.C., Johnson, C.A., \& Rojas, C. 2010. Eliciting risk preferences: When is simple better? Journal of Risk and Uncertainty, 41(3), 219-243.

Donovan, D.M., \& Marlatt, G.A. (1982). Personality subtypes among driving-while-intoxicated offenders: Relationship to drinking behavior and driving risk. Journal of Consulting and Clinical Psychology, 50(2), 241-249. 
Ensor, T., \& Godfrey, C. (1993). Modelling the interactions between alcohol, crime and the criminal justice system. Addiction, 88(4), 477-487.

Euser, A.S., van Meel, C.S., Snelleman, M., \& Franken, I.H.A. (2011). Acute effects of alcohol on feedback processing and outcome evaluation during risky decision-making: an ERP study. Psychopharmacology, 217(1), 111-125.

Ferguson, D.M., \& Horwood, L.J. (2000). Does cannabis use encourage other forms of illicit drug use? Addiction, 95(4), 505-530.

Finnigan F, Hammersley R, \& Millar K (1995). The effects of expectancy and alcohol on cognitivemotor performance. Addiction, 90(5), 661-672.

Fromme, K., Katz, E., \& D'Amico, E. (1997). Effects of alcohol intoxication on the perceived consequences of risk taking. Experimental and Clinical Psychopharmacology, 5(1), 14-23.

George, S., Rogers, R.D., \& Duka, T. (2005). The acute effect of alcohol on decision making in social drinkers. Psychopharmacology, 182(1), 160-169.

Goodman, R.A., Mercy, J.A., Loya, F., Rosenberg, M.L., Smith, J.C., Allen, N.H. Vargas, L., \& Kolts, R. (1986). Alcohol Use and Interpersonal Violence: Alcohol Detected in Homicide Victims. American Journal of Public Health, 76(2), 144-149.

Gustafson, R., \& Källmén, H. (1990). Alcohol and the compensation hypothesis: a test with cognitive and psychomotor tasks. Perceptual and Motor Skills, 71, 1367-1374.

Halpern-Felsher, B.L., Millstein, S.G., \& Ellen, J.M. (1996). Relationship of alcohol use and risky sexual behavior: a review and analysis of findings. Journal of Adolescent Health, 19(5), 331-336.

Harrison, G., \& List. J. (2004). Field experiments. Journal of Economic Literature, 42(4), 1009-1055.

Isen, A.M., \& Patrick, R. (1983). The effect of positive feelings on risk taking: When the chips are down. Organizational Behavior and Human Performance, 31(2), 194-202.

Kahn, B.E., \& Isen, A.M. (1993). The Influence of Positive Affect on Variety Seeking Among Safe, Enjoyable Products. Journal of Consumer Research, 20(2), 257-270.

Kyngdon, A., \& Dickerson, M. G. (1999). An experimental study of the effect of prior consumption of alcohol on a simulated gaming activity. Addiction, 94(5), 697-707.

Lane, S.D., Cherek, D.R., Pietras, C.J., \& Tcheremissine, O.V. (2004). Alcohol effects on human risk taking. Psychophachology, 172(1), 68-77.

Lau, M.A., Pihl, R.O., \& Peterson, J.B. (1995). Provocation, acute alcohol intoxication, cognitive performance, and aggression. Journal of Abnormal Psychology, 104(1), 150-155.

Marlatt, G.A., \& Rohsenow, D.J. (1980). Cognitive processes in alcohol use: expectancy and the balanced placebo design. In Advances in Substance Abuse: Behavioral and Biological Research, Mello NK (ed.). JAI Press: Greenwich, CT.

McMillen, L., \& Wells-Parker, E. (1987). The effect of alcohol consumption on risk-taking while driving. Addictive Behaviors, 12(3), 241-247.

Meier, S.E., Brigham, T.A., Ward, D.A., Meyers, F., \& Warren, L. (1996). Effects of blood alcohol concentrations on negative punishment: Implications for decision making. Journal of Studies on Alcohol, 57(1), 85-96. 
Mitchell, M.C. (1985). Alcohol-induced impairment of central nervous system function: Behavioral skills involved in driving. Journal of Studies on Alcohol, 10(Suppl.), 109-116.

Moore, S.C., \& Chater, N. (2003). The Influence of Affect on Risky Behavior: From the Lab to Real World Financial Behavior Decision Technology Research Group, Department of Psychology, Warwick University Coventry, CV4 7AL, UK.

Moskovitz, H., \& Robinson, C.D. (1988). Effects of low doses of alcohol on driving-related skills: A review of the evidence in US. Department of Transportation National Highway, Traffic Safety Administration.

Peck, R.C., Gebers, M.A., Voas, R.B., \& Romano, E. (2008). The relationship between blood alcohol concentration (BAC), age and crash risk. Journal of Safety Research, 39(3), 311-319.

Richardson, A., \& Budd, T. (2003). Young adults, alcohol, crime and disorder. Criminal Behaviour and Mental Health, 13(1), 5-16.

Ross, D.F. \& Pihl, R.O. (1989). Modification of the balanced-placebo design for use at high blood alcohol levels. Addictive Behaviors, 14(1), 91-97.

Russ, N., Geller, E.S., \& Leland, L.S. (1988). Blood-alcohol level feedback: a failure to deter impaired driving. Psychology of Addictive Behaviors, 2(3), 124-130.

Sabater-Grande, G., \& Georgantzís, N. (2002). Accounting for risk aversion in repeated prisoners' dilemma games: an experimental test. Journal of Economic Behavior \& Organization, 48(1), 37-50.

Sjoberg, L. (1969). Alcohol and gambling. Psychopharmacology, 14(4), 284-298.

Slovic, P. (1969). Differential effects of real versus hypothetical payoffs on choices among gambles. Journal of Experimental Psychology, 80(3), 434-437.

Smith, V.L. (1976). Experimental Economics: Induced Value Theory. American Economic Review, 66(2), 274-279.

Stroop, J.R. (1935). Studies of interference in serial verbal reactions. Journal of Experimental Psychology, 18, 643-661.

Testa, M., \& Collins, L.R. (1997). Alcohol and risky sexual behavior: Event-based analyses among a sample of high-risk women. Psychology of Addictive Behavior, 11(3), 190-201.

Thombs, D.L., Olds, R.S., \& Snyder, B.M. (2003). Field assessment of BAC data to study late-night college drinking. Journal of Studies of Alcohol, 64, 322-330.

Weber, E.U. (1997). The utility of measuring and modeling perceived risk. In Choice, Decision, and Measurement: Essays in Honor of R. Duncan Luce, Marley AAJ (ed.). Erlbaum: Mahwah, NJ. pp. 45-57.

Zador, P.L., Krawchuk, S.A., \& Voas, R.W. (2000). Alcohol-related relative risk of driver fatalities in relation to driver age and gender: an update using 1996 data. Journal of Studies on Alcohol, 61(3), 389-395. 


\section{Supporting Figures}

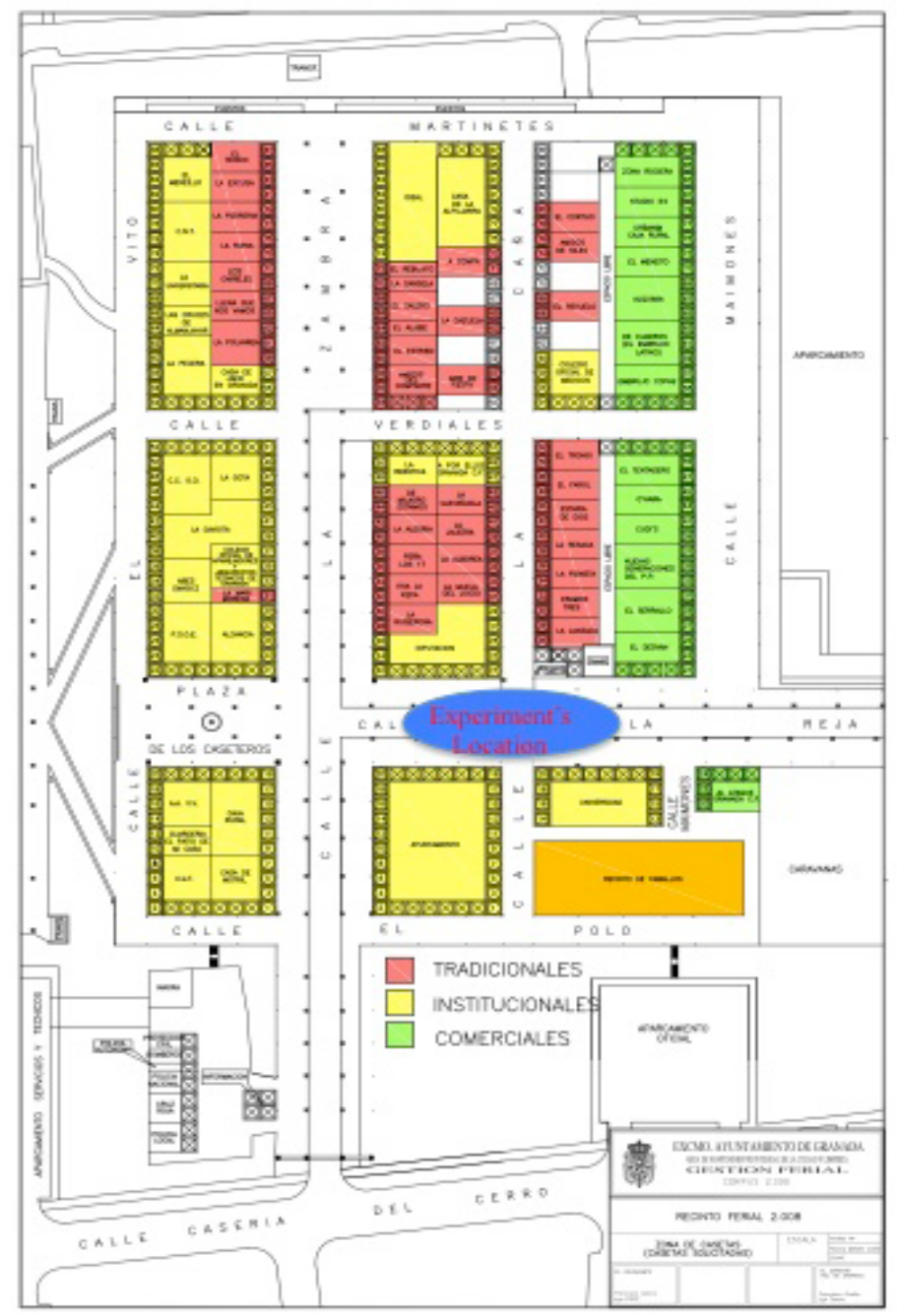

Figure S1. Map of "Feria Corpus del Christi 2008". The experiment took place around the main entrance to the university kiosk (highlighted blue area).

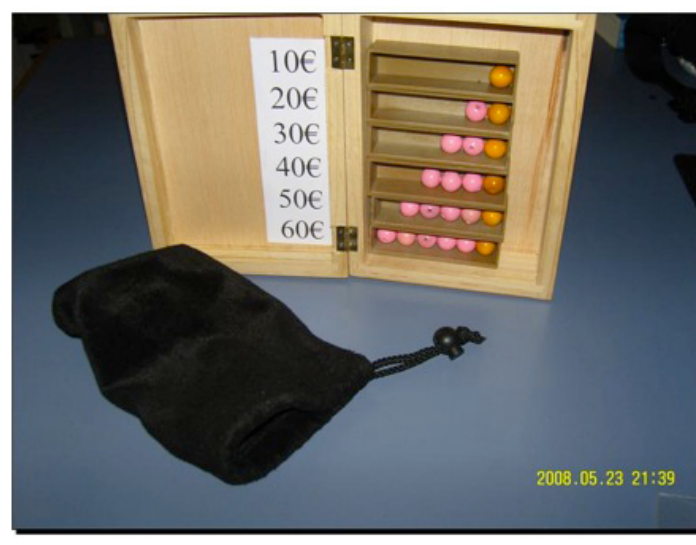

Figure S2. Lottery boxes 


\begin{tabular}{|c|c|c|c|c|}
\hline \multicolumn{5}{|c|}{ Ordered Logistic Regressions excluding Outliers } \\
\hline \multirow{2}{*}{$\begin{array}{l}\text { Dep. Variable: } \\
\text { lottery choice }\end{array}$} & \multicolumn{2}{|c|}{ Main effects } & \multicolumn{2}{|c|}{ Interaction effects } \\
\hline & (2) & (3) & (5) & (6) \\
\hline \multicolumn{5}{|l|}{ BAC } \\
\hline$e \mathrm{BAC}$ & $\begin{array}{c}-1.560^{* *} \\
(0.684)\end{array}$ & & $\begin{array}{c}-5.489 * * \\
(2.434)\end{array}$ & \\
\hline underBAC & & $\begin{array}{c}0.396 \\
(0.710)\end{array}$ & & $\begin{array}{l}5.498 \\
(3.42)\end{array}$ \\
\hline \multicolumn{5}{|l|}{ BAC $x$ male } \\
\hline$e \mathrm{BAC} \times$ age & & & $\begin{array}{l}0.131 * \\
(0.078)\end{array}$ & \\
\hline underBAC $\mathrm{x}$ male & & & & $\begin{array}{c}6.077 * * * \\
(1.848)\end{array}$ \\
\hline underBAC $x$ age & & & & $\begin{array}{c}-0.325 * * * \\
(0.117)\end{array}$ \\
\hline male & $\begin{array}{c}0.432 \\
(0.712)\end{array}$ & $\begin{array}{c}0.445 \\
(0.771)\end{array}$ & $\begin{array}{c}0.471 \\
(0.731)\end{array}$ & $\begin{array}{c}0.981 \\
(1.010)\end{array}$ \\
\hline age & $\begin{array}{c}0.690 * * * \\
(0.215)\end{array}$ & $\begin{array}{l}0.099 * \\
(0.052)\end{array}$ & $\begin{array}{l}0.589 * * \\
(0.236)\end{array}$ & $\begin{array}{l}1.107 * * \\
(0.441)\end{array}$ \\
\hline $\operatorname{age}^{2}$ & $\begin{array}{c}-0.009 * * * \\
(0.003)\end{array}$ & & $\begin{array}{c}-0.008^{* *} \\
(0.003)\end{array}$ & $\begin{array}{c}-0.016 * * \\
(0.007)\end{array}$ \\
\hline BMI & $\begin{array}{c}0.095 \\
(0.093)\end{array}$ & $\begin{array}{c}0.152 \\
(0.101)\end{array}$ & $\begin{array}{c}0.070 \\
(0.095)\end{array}$ & $\begin{array}{l}0.277 * * \\
(0.118)\end{array}$ \\
\hline alc. habits (drinks) & $\begin{array}{l}-0.027 \\
(0.084)\end{array}$ & $\begin{array}{l}-0.156 \\
(0.088)\end{array}$ & $\begin{array}{c}0.013 \\
(0.087)\end{array}$ & $\begin{array}{c}-0.253 * * \\
(0.105)\end{array}$ \\
\hline marijuana & $\begin{array}{l}-0.243 \\
(0.746)\end{array}$ & $\begin{array}{c}0.075 \\
(0.815)\end{array}$ & $\begin{array}{l}-0.391 \\
(0.761)\end{array}$ & $\begin{array}{l}-0.068 \\
(0.932)\end{array}$ \\
\hline party session & $\begin{array}{c}0.510 \\
(0.533)\end{array}$ & $\begin{array}{c}0.438 \\
(0.598)\end{array}$ & $\begin{array}{c}0.521 \\
(0.761)\end{array}$ & $\begin{array}{l}2.881^{* *} \\
(1.166)\end{array}$ \\
\hline party ses. $\mathrm{X}$ male & & & & $\begin{array}{c}-3.138 * * \\
(1.386) \\
\end{array}$ \\
\hline observations & 68 & 53 & 68 & 53 \\
\hline $\operatorname{LR}\left(\mathrm{chi}^{2}\right)$ & $20.62 * *$ & $19.38^{* *}$ & $23.75^{* * *}$ & $40.59 * * *$ \\
\hline pseudo $\mathrm{R}^{2}$ & 0.0926 & 0.1117 & 0.1066 & 0.2339 \\
\hline
\end{tabular}

Table S1: The impact of BAC and self-estimated BAC over the willingness to take risk. Ordered Logistic Regressions. eBAC outliers are excluded. We consider outliers those observations situated three or more standard deviations from the mean. For eBAC (but not for BAC) two observations are classified as outliers. Standard errors in brackets. $*, * *, * * *$ indicate significance at the $0.10,0.05$, and 0.01 levels, respectively. The sample in models 3 and 6 are reduced to those subjects having declared having ingested alcohol before the experiment. 


\begin{tabular}{lccc}
\hline \multirow{2}{*}{$\begin{array}{l}\text { Dep. Variable: } \\
\text { underBAC }\end{array}$} & \multicolumn{3}{c}{ Ordinary Least Squares } \\
\hline \hline \multirow{2}{*}{ BAC } & $0.640^{* * *}$ & $0.744^{* * *}$ & $0.553^{*}$ \\
& $(0.145)$ & $(0.180)$ & $(0.287)$ \\
male & 0.061 & & \\
& $(0.174)$ & & \\
age & $-0.022^{*}$ & $-0.028^{* *}$ & -0.023 \\
& $(0.012)$ & $(0.014)$ & $(0.028)$ \\
BMI & -0.011 & -0.009 & -0.021 \\
& $(0.022)$ & $(0.021)$ & $(0.076)$ \\
alc. habits & -0.026 & $-0.042 *$ & -0.066 \\
& $(0.024)$ & $(0.021)$ & $(0.100)$ \\
marijuana & 0.239 & -0.128 & -0.240 \\
& $(0.216)$ & $(0.202)$ & $(0.709)$ \\
party session & 0.121 & 0.041 & 0.139 \\
& $(0.142)$ & $(0.139)$ & $(0.354)$ \\
alc. experience & 0.003 & 0.052 & -0.103 \\
& $(0.032)$ & $(0.034)$ & $(0.085)$ \\
constant & 0.405 & 0.606 & 0.957 \\
& $(0.470)$ & $(0.517)$ & $(1.131)$ \\
\hline \hline observations & 55 & 34 & 21 \\
F & $3.96 * * *$ & $4.85 * * *$ & 1.28 \\
R ${ }^{2}$ & 0.4077 & 0.5663 & 0.4081 \\
\hline
\end{tabular}

Table S2: Understimation (underBAC) of one's own BAC. OLS regressions. Standard errors in brackets. *, $* *, * * *$ indicate significance at the $0.10,0.05$, and 0.01 levels, respectively. The sample is reduced to those subjects who declared having ingested alcohol before the experiment. Due to the reduced sample size no interaction effects are added to the model. $\mathrm{Age}^{2}$ is excluded since it was found to be insignificant. 